\title{
ACHIEVING OPERATIONAL EXCELLENCE BY IMPLEMENTING AN ERP (ENTERPRISE RESOURCE PLANNING) SYSTEM (A CASE STUDY OF A LARGE SCALE INDUSTRY)
}

\author{
S.S. Kuber ${ }^{1}$, Babasaheb P. Raut ${ }^{2}$ \\ ${ }^{I}$ Professor, Department of Industrial \& Production Engineering, Vishwakarma Institute of Technology, Pune \\ ${ }^{2}$ M. Tech. (Industrial Engg), Vishwakarma Institute of Technology, Pune
}

\begin{abstract}
The objective of this research paper is to study the benefits in terms of operational excellence after implementing of an ERP system in a large scale industry (Filters Manufacturer). The study contains the functions from 'Inventory', 'Procurement', 'Order Management' \& 'Mobile Supply Chain'. Enterprise resource planning (ERP) software integrates key business and management processes within and beyond a firm's boundary. An ERP system has the potential to seamlessly integrate various processes and functions of an organization, and generate a comprehensive picture of an entire company.
\end{abstract}

Traditional methods of doing the business are too slow for the industry which is trying to compete against electronic. The paper highlights the benefits mainly in- i) Processing Time ii) Manpower Reduction iii) Reduction in Audit Frequency iv) Inventory Traceability v) Availability of Data \& Reporting Advantages vi) Month End Closures / Reconciliations \& Year End Closure vii) Operational Excellence \& Productivity Improvements

Keywords- Enterprise Resource Planning, Operational Excellence

\section{INTRODUCTION}

The global market for enterprise resource planning (ERP) has registered a significant growth in last two decades. The global ERP market's revenue were estimated $\$ 65$ Billion plus in 2012. Early ERP systems implementer's deployed modules primarily addressed intra-firm activities in the finance, logistics \& human resource functions of the organizations. As Intra-firm ERP implementations stabilized then company targets to implement the modules which are inter-firm. Because of expanding customer demand, ERP vendors continue to add their product lines by offering ERP systems that have more depth, complexity, and modular integrations. ERP implementation results in improvement in operational performance \& enables firms to standardize, integrate, and streamline their data and process flows. This also provides critical information streams necessary for effective decisionmaking.

In this study, we seek to advance this stream by implementing an ERP system for a large scale filter manufacturing firm \& observe the operational performance at various stages. We believe that our investigation of individual and systematic ERP implementations can provide an improved picture of an ERP system to the firm. Paper is organized in such a way that in the first section it gives the objective \& implementation phases of an ERP system. Also before implementing an ERP system, we had taken the data of the objectives respectively an analyzed / compared after go live. We observed the readings for 4 months after go live and mentioned the conclusions and results in the second section of this paper. Also the graphs are included wherever necessary in this paper on the basis of collection of the data from the respective sites for the industry.

\subsection{Objectives:}

Improve operational excellence \& productivity by-

1. Reduce Processing Time

2. Reduce Manpower

3. Reduction in Audit Frequency

4. Inventory Traceability

5. Availability of Data \& Reporting Advantages

6. Month End Closures / Reconciliations \& Year End Closure

Objective of the company is to implement the Oracle eBusiness Suite Application (ERP Applications) to achieve the above effect at various departments.

\section{IMPLEMENTATION ETHODOLOGY}

Various ERP uses their implementation methodologies while implementing an ERP system. At 'Filter Manufacturer', AIMS (Application Implementation Methodology) methodology has been used. It mainly comprises steps as below- 
1. Business Requirement Gathering

2. As Is Study

3. To Be Process

4. Configuration / Development

5. Testing

6. User Acceptance Testing (UAT)

7. Documentation
8. Training to Super Users \& Users

9. Go Live

10. Infant Care

11. Post Implementation Support

Table 1 Departments \& it's some of the functions

\begin{tabular}{|l|l|}
\hline Functions & Department \\
\hline Requisitions & Purchasing \\
\hline Request for Quotations & Purchasing \\
\hline Quotations & Purchasing \\
\hline Purchase Order & Purchasing \\
\hline PO Receipts & Purchasing \\
\hline Payments & Accounts Payables \\
\hline Sub-Inventory Transfers & Inventory \\
\hline Inter Organization Transfers & Inventory \\
\hline Issue Material to Assembly & Inventory \\
\hline Return Material from Assembly to Inventory & Inventory \\
\hline Return Material from Inventory to Supplier & Purchasing \\
\hline Cycle Counting & Inventory \\
\hline Physical Inventory & Inventory \\
\hline Min Max Planning & Inventory \\
\hline Material Requirement Planning & MRP \\
\hline Sales Orders & Order Management \\
\hline Sales Order Allocations & Inventory \\
\hline Picking & Inventory \\
\hline Packing & Order Management \\
\hline Shipping & Order Management \\
\hline & \\
\hline
\end{tabular}

\section{AS IS STUDY OBSERVATIONS}

As is study mainly contains the existing business process study at corporate sites, manufacturing units, inventory organizations, warehouses \& service locations. In this implementation functional consultants have prepared a questionnaire to discuss \& capture the as is processes in the 'Filtration Business Unit' with business super users.

Main process in this research paper has been highlighted and summarized from 'Inventory Management', 'Purchasing' \& 'Order Management' areas.

Processes- 1.Procurement- A decentralized procurement process in a very traditional way without any software or electronic way is being used. Due to the decentralized purchasing lots of manpower is being used at various sites.
Also the same material at different sites being procured from different suppliers hence there is no scope of discounts from supplier or suppliers. For processing a single purchase order there has to be a communication \& lots of follow ups with suppliers. Also for internal approval of a purchase order there seems to be a process time of near about 1 day, as this is a manual process. Initially requisitions are being raised on a manual template. It gets approved by a supervisor $\&$ then it reaches to the buyer. All the requisitions are processed manually \& for the items quotations are requested from supplier. Once supplier sends the quotations, after analyzing those are processed. Then the purchase order is raised against the approved suppliers in a traditional way on the paper format. Hence the processing time of a document is very high $\&$ sometimes create an issue to get the material at the plant hence shipments are delayed and customer gets dissatisfied. 2.Inventory- In inventory there are many processes being used 
since from material receiving, inspection (acceptance \& rejection), material transfer from one Subinventory to another Subinventory, from one organization to another organization, material issue to line. Also company uses cycle counting, physical inventory. There are two different inventory organizations which has RAW Material, FGI sub inventories respectively. Physical inventory currently is being arranged twice every year as to count the physical inventory and reconcile manually \& make necessary adjustments at finance side. This is a very crucial process as of now as inventory size is big. Also inventory planning is one of the major processes for every inventory management. Currently there is a legacy system which is used for planning.

\subsection{Functions \& Head Counts}

In as is study, we had a look on the existing functions \& head counts who are involved in day to day work. There are more resources involved in day to day work \& summarized it as below-

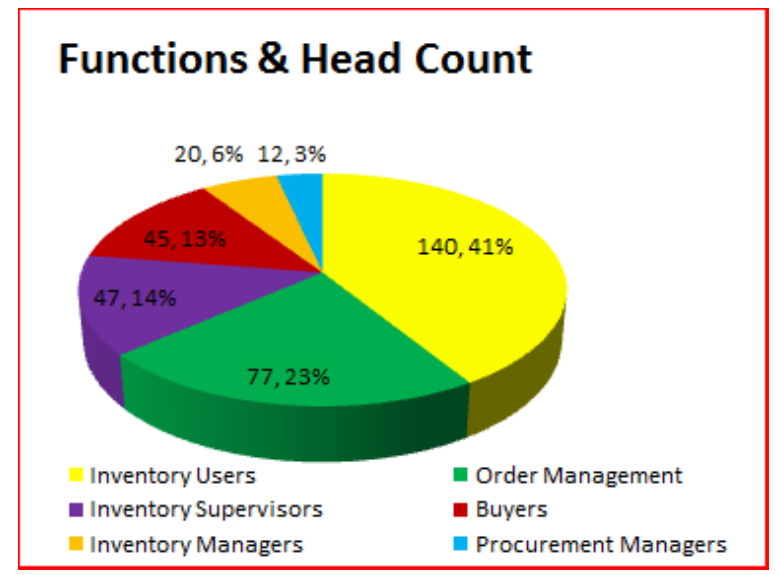

Fig 1 Functions \& Head Count

\subsection{Audit Frequency}

Audit frequency for all the departments is very high \& it consumes lots of time as manual work and papers needs to be audited. Average frequency per site is $2.1 \& 2.2$.

Table 2 Audit Frequency

\begin{tabular}{|l|l|l|}
\hline \multicolumn{2}{|l|}{ Audit For } & \multicolumn{2}{l|}{} \\
\hline & Site1 & Site2 \\
\hline $\begin{array}{l}\text { Year } \\
(2013)\end{array}$ & Frequency & Frequency \\
\hline Jan'13 & 2 & 2 \\
\hline Feb'13 & 3 & 2 \\
\hline Mar'13 & 2 & 2 \\
\hline Apr'13 & 2 & 3 \\
\hline
\end{tabular}

\begin{tabular}{|l|l|l|} 
May'13 & 2 & 2 \\
\hline Jun'13 & 2 & 2 \\
\hline Jul'13 & 2 & 2 \\
\hline Aug'13 & 2 & 3 \\
\hline Sep'13 & 2 & 2 \\
\hline Average & 2.11 & 2.22 \\
\hline
\end{tabular}

Audit in terms of checking random transactions / documents in term of purchase orders, receipts, material transfers \& material receipt. Once we analyzed we came to know lots of documents and cross questioning happens in the audits. And auditors won't get the desired inputs in terms of concrete reports etc.

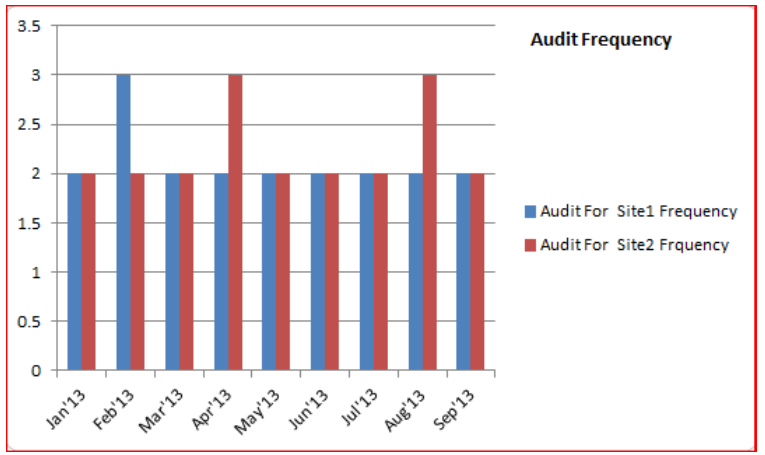

Fig 2 Audit Frequency at Site $1 \&$ Site2

\subsection{Inventory Traceability}

Inventory traceability is a big challenge currently and every time user needs big amount of time to find out a part in the inventory. There are no default locations defined for a specific part while receiving. Any part is getting anywhere stored. There is a lot of scope to redesign the process of inventory storage before implementing.

No of occurrences since Jan 2013 that users unable to trace the item in inventory and reported to the immediate supervisor-

Table 3 Events Occurred Unable to Trace Inventory

\begin{tabular}{|l|l|l|}
\hline \multicolumn{3}{|c|}{ Events Occurred Inventory Traceability } \\
\hline & Site1 & Site2 \\
\hline Year(2013) & Events & Events \\
\hline Jan'13 & 21 & 16 \\
\hline Feb'13 & 16 & 13 \\
\hline Mar'13 & 4 & 8 \\
\hline Apr'13 & 19 & 14 \\
\hline May'13 & 14 & 19 \\
\hline Jun'13 & 15 & 11 \\
\hline
\end{tabular}




\begin{tabular}{|l|l|l|} 
Jul'13 & 5 & 23 \\
\hline Aug'13 & 20 & 17 \\
\hline Sep'13 & 18 & 19 \\
\hline Average & 14.66 & 15.55 \\
\hline
\end{tabular}

Similar analysis has been presented in a graphical way-

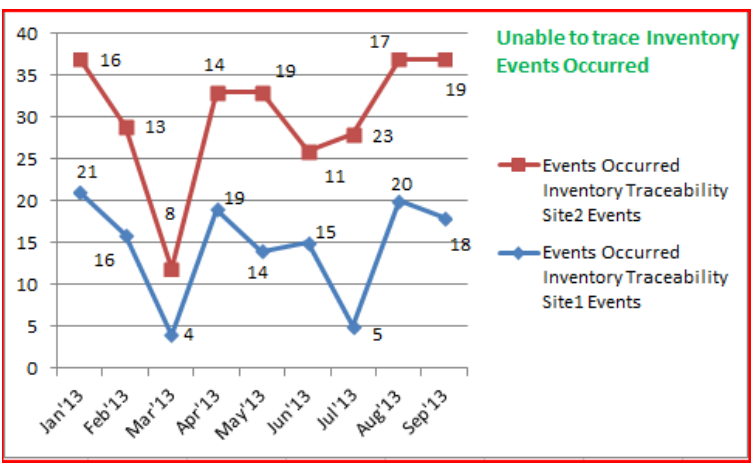

Fig 3 Unable to trace Inventory

\subsection{Availability of Data \& Reporting Advantages}

In as is study, we found that there is no availability of data in a concrete manner to represent to the management \& management cannot take the concrete decision. Hence it includes lots of manpower and repetitive work to get out the details from the documents and represent it to the management. The similar data needs to be represented in different analysis for the top management to decide the way ahead. So this is also one of the crucial tasks for the business to look into and super users struggle a lot to get the data in a presentable manner.

\subsection{Month End Closures \& Year End Closures}

For every organization it is very important that every month all the accounting periods gets successfully closed to identify the month on month revenue \& profit, expense \& assets \& publish it to the share markets on quarterly basis. So that public can invest more in the company in the form of share. If a company unable to provide the quarterly performance, then public may fear there is some crisis going on and any delay in this, public invest in another company.

Table 4 Month End Closure Time Taken

\begin{tabular}{|l|ll|l|}
\hline \multicolumn{2}{|l|}{ Month End Closure } & \\
\hline & Site1 & Site2 \\
\hline Year(2013) & $\begin{array}{l}\text { Time } \\
(\text { Hrs })\end{array}$ & $\begin{array}{l}\text { Time Taken } \\
(\text { Hrs })\end{array}$ \\
\hline Jan'13 & 49 & 38 \\
\hline Feb'13 & 52 & 63 \\
\hline
\end{tabular}

\begin{tabular}{|l|l|l|} 
Mar'13 & 45 & 48 \\
\hline Apr'13 & 39 & 37 \\
\hline May'13 & 37 & 46 \\
\hline Jun'13 & 43 & 45 \\
\hline Jul'13 & 31 & 29 \\
\hline Aug'13 & 45 & 27 \\
\hline Sep'13 & 38 & 35 \\
\hline Average & 42.11 & 40.88 \\
\hline
\end{tabular}

Above table, shows figures time taken for site1 \& site2 respectively. As compare to other organizations which uses ERP software, the time taken for monthly closure is very high. The similar has been presented in a graphical way as below-

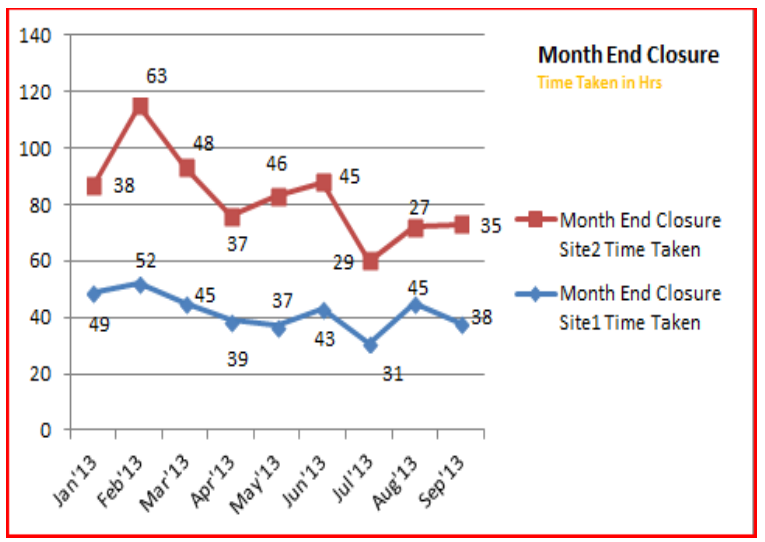

Fig 4 Month End Closure

Similarly, yearend closure is very much important as the results for the financial year will be published by the company. At year end closure, it is consolidated result for all the months within that financial year.

\section{TO BE PROCESS}

This is the actual phase where we design the process map after studying the existing process. This covers the documentation part where we list down all the processes and create workflows in a diagrammatical format. We have considered, inventory processes, purchasing processes \& order management processes.

Prior to design any process, we need to make sure that the Organization Structure is designed to suite the business. And the data will flow from bottom to top in a successful manner how business wants to be. Once the organization structure is ready, then for individual module we need to make sure that it is configured as per the business processes which are captured in as is study. 


\subsection{Procurement Processes}

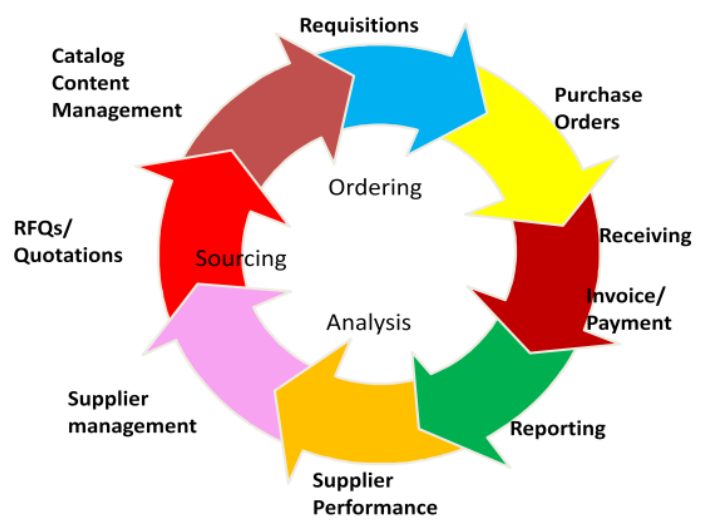

Fig 5 Procurement Cycle

We have considered the procurement lifecycle and as per it, we have configured the necessary parameters for it in Oracle e-Business Suite Application. These are mainly, Financial Options, Purchasing Options, Receiving Parameters, Line Types, Buyers, and also we developed some reports apart from seeded for procurement department. Mainly we configured 'Standard Purchase Order', 'Planned Purchase Order', 'Blanket Purchase Agreement', Contract Purchase Agreement'. Below figure differences have been summarized in between these purchase order types. Accordingly the configuration for each purchase order has been defined in the system. These setups are one time setups and not necessary to change every time. If there is any change in business process then accordingly the setups needs to be changed. Also hierarchy has been defined. This hierarchy will help to approve all the purchase related documents like purchase orders. This hierarchy has been setup on the basis of position and limits in terms of money for each position. Below table shows the comparison in between the above mentioned purchase order types in a summary -

Table 5 Comparison of Diff Types of POs

\begin{tabular}{|c|c|c|c|c|}
\hline \multicolumn{5}{|c|}{ Comparison of Different Types of Purchase Order } \\
\hline Parameters & SPO & $\mathrm{PPO}$ & BPA & $\mathrm{CPA}$ \\
\hline $\begin{array}{l}\text { Terms and Conditions } \\
\text { Known }\end{array}$ & Yes & Yes & Yes & Yes \\
\hline $\begin{array}{l}\text { Goods and Services } \\
\text { Known }\end{array}$ & Yes & Yes & Yes & No \\
\hline Pricing Known & Yes & Yes & $\begin{array}{l}\text { May } \\
\text { Be }\end{array}$ & No \\
\hline Quantity Known & Yes & Yes & No & No \\
\hline $\begin{array}{l}\text { Deliver } \quad \text { Schedule } \\
\text { Known }\end{array}$ & Yes & $\begin{array}{l}\text { May } \\
\text { Be }\end{array}$ & No & No \\
\hline $\begin{array}{l}\text { Account Distribution } \\
\text { Known }\end{array}$ & Yes & Yes & No & No \\
\hline
\end{tabular}

\begin{tabular}{|l|l|l|l|l|} 
Can be Encumbered & Yes & Yes & No & No \\
\hline $\begin{array}{l}\text { Releases can be } \\
\text { Encumbered }\end{array}$ & N/A & Yes & Yes & No \\
\hline
\end{tabular}

\subsection{Inventory Processes}

This module is the key module \& being referenced most of the other modules. The basic setup structures for inventory module are - Define key flex fields, work day calendar, transaction types, source types, inventory accuracy methods, inventory planning methods like Min Max Planning, Re-Order Point Planning', Cycle Counting, Physical Inventory and so on. In inventory accuracy we have configured the items as per the requirement in - Item Revision Control, Item Locator Control, Item Serial Control, Item Lot Control. While performing the transactions, if an item is under any one control, you need to provide the extra information about it while performing the transaction. Eg. If an item is serial control, then while performing a transaction in the system, user needs to provide item serial control. This captures each and every transactions detail for reporting purpose.

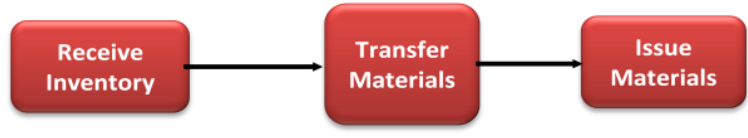

Fig 6 Receipt to Issue Cycle

Also, few items has been put under min max planning method as per the business requirement to order the economic order quantity. Implementation team has developed the report likeInventory Valuation Report, Material Transaction Report, Cycle Counting Listing Report, Physical Inventory Adjustment Report etc..

\subsection{Order Management Processes}

In Order Management, we configure order line types, order types, pricing, give the grants to the order processors. According to the process, we have configured the order management module as per the business requirement. Order types configured as - Standard Order, Return Material Authorization (RMA) Order i.e. nothing but the customer returns and Drop Shipment. These three orders cover the business requirement. Below figure shows 'Order to Cash' cycle.

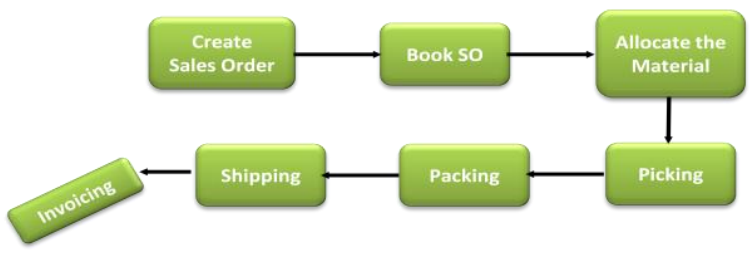

Fig 7 Order to Cash Cycle 
With the above mentioned module, we have configured the 'Mobile Supply Chain Applications', which again gives the flexibility to perform the transactions anywhere in the plant via a RFHHD (Radio Frequency Hand Held Device). User is not required to note down the transactions and again perform it via going back to his desktop. User can perform the transactions from anywhere in the plant where the wireless network is available. This covers most of the design and configuration part in the implementation supply chain modules for a filtration manufacturing industry.

\subsection{Functional Testing, UAT \& Documentation}

This is one of the most important phases of any implementation project life cycle. Implementation team and testing team performs each and every test as per the business processes mapped. If any test fails the results are collected and according the objects needs to be fixed or the correction in configuration of the setups needs to be performed. If testing is done properly, after go live there will be no issues \& less impact on customer operations. First team has prepared a test plan and a template, each business process has been documented in the template for testing purpose. Also the observations and findings have been incorporated in the results column. Once implementation team tests all the functional areas, business users needs to test it and it is called as 'User Acceptance Testing'. UAT confirms the user's acceptance according the business requirements and users or super users give the confirmation \& sign off the UAT phase. In this project, UAT duration was around 20 days.

The documentation part, in any implementation plays an important role. The time to time updating of the document is useful to the implementation team members as well as business.

\subsection{Go Live}

For every change there is a oppose, hence while going live also most of the employee oppose the change. Go live is a cutoff date to stop a legacy system transactions or manual transactions and start capturing the transactions in the newly live system. Go live means going live with the newly implemented applications. Before go live there are so many preparations like training users, data migrations or historical data bringing in the new system. These are nothing the prerequisites for going live. After go live immediate application support is known as 'Infant Care' \& then post implementation support. In post implementation support generally the application related issues faced by users are addressed and fixed by means of code fixes or work around. In next session we are going to see the results and conclusions.

\section{RESULTS AND CONCLUSIONS}

ERP system represents a significant investment and major source of operational performance improvement for firm. After go live of an ERP system below are the improvements -

\subsection{Functions and Head Counts:-}

It has been observed that after implantation we see the head counts has been decreased drastically. These resources are being utilized in different roles and position now according to their skills. In the graph we can see the respective areas and it's head count. In inventory it is 60, Order Management- 30, Buyers- 23, Inventory supervisors- 21, Inventory Managers12, and Procurement Managers-5.

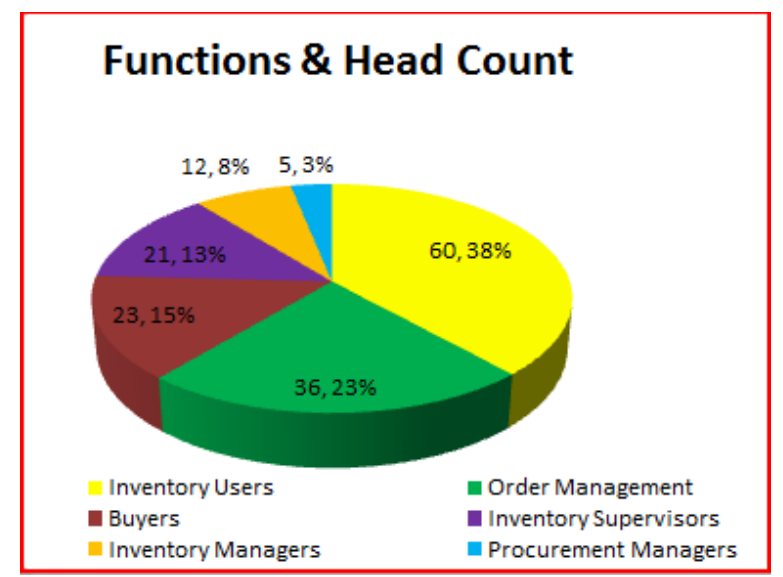

Fig 8 Functions and Head Count After

\subsection{Audit Frequency}

Audit frequency has been reduced quarterly once. As a single database, auditors can access all the material transactions, financial reports \& compare with the help of system generated reports. Hence work became very simple and accurate.

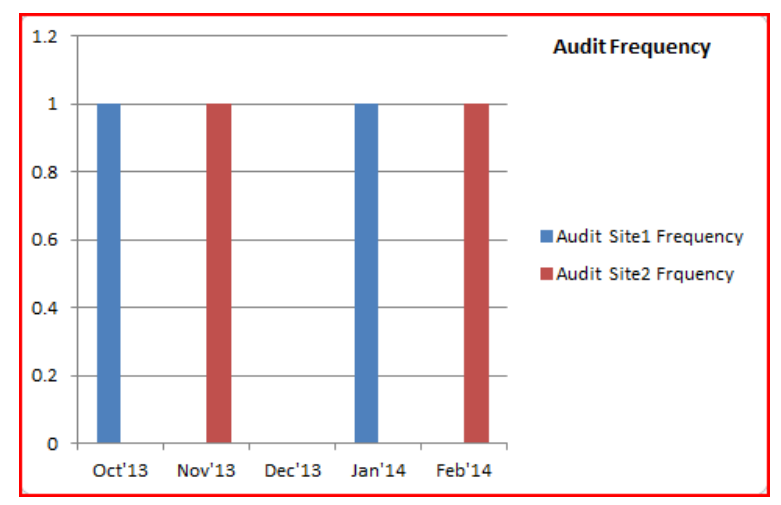

Fig 9 Audit Frequency After

We can see the audit frequency has been reduced to quarterly once for a site. 


\subsection{Inventory Traceability}

After go live with 'Mobile Application' it has been observed that zero occurrences to unable to trace the inventory.

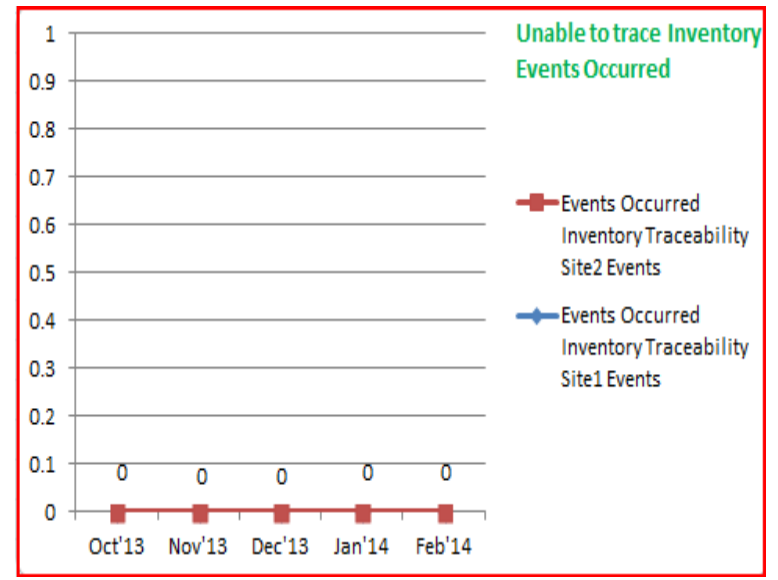

Fig 10 Unable to Trace Inventory After

Radio frequency hand held device able to trace the inventory once we enter the item details and inquiry it. How it works-

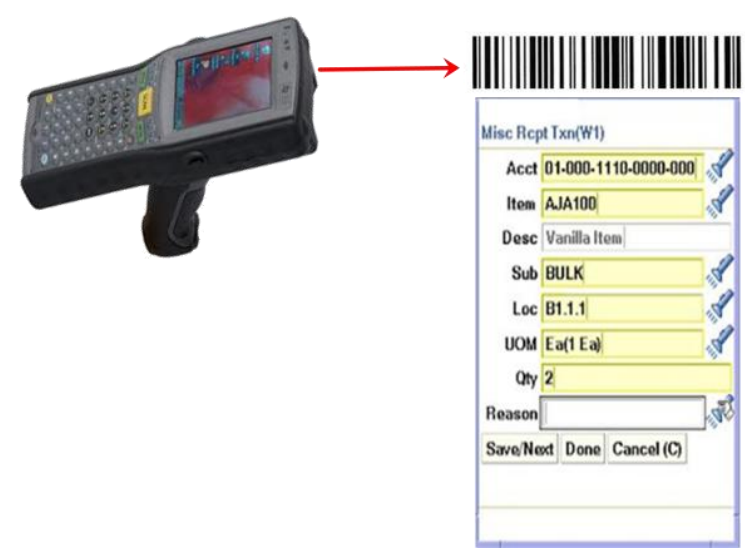

Fig 11 Inventory Traceability After

A hand held device reads the barcode and populate the details in the field for processing the transaction. Hence accuracy in the system is increased and productivity has been increased. Similar way for tracing a part within an inventory, user needs to navigate to the 'Inquiry' screen and enter the required details of an item and search. System will show you the details where the part was received and which location within an inventory it has been placed.

\subsection{Availability of Data \& Reporting Advantage}

With the single database, multiple site information is stored at a place. Hence data availability for all sites and location is available at one click. The custom reports have been developed for the analysis of management and decision making. The access of the respective reports has been given the respective roles and positions. So that the data security is maintained and particular information is only viewable to respective person with that position.

\subsection{Month End Closure \& Year End Closure:-}

Before implementation of an ERP system, average time for month end closure was 48 \& 40 hours for site $1 \& 2$ respectively. If we see the below

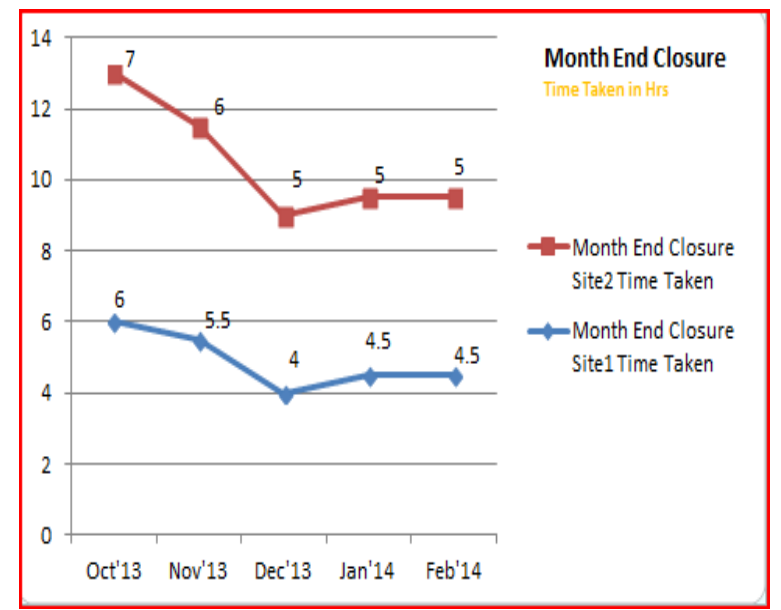

Fig 12 Month End Closure

If we see the graph, the time for month end closure has been reduced drastically. This is possible due to an effective ERP system.

\section{CONCLUSIONS}

ERP system has played a major role in improving each process within the industry. Also it has given the more power to all the users and super users. Also this study indicates that a systematic ERP implementation contribute an operational performance changes. It is important that managers focus holistic integrations to derive maximum gains. Also, it indicates performance improvement in each area where the functions of ERP are being used. Hence as a consolidation we see that operational performance and productivity has been increased.

\section{REFERENCES}

[1] R.Panneerselvam, Production and Operations Management,3rd ed. PHL Learning Pvt. Ltd

[2] Oracle Unversity, Oracle Inventory User Guide,Release R12,Oracle University, USA

[3] Oracle University, Oracle Purchasing User Guide, Release R12, Oracle Unviersity, USA. 
[4] Oracle University, Oracle Order Management User Guide, Release R12, Oracle Unveristy, USA.

[5] Michael F., A Project Approach to Enterprise Resource Planning Implementation, Internantional Journal of Business Managmeent, Vol.7, No.10;May2012

[6] Severine Le Loarne, Working with ERP systems- Is big brother back?, Science Direct, Computers in Industry 56 (2005) 523-528

[7] Shahneel Baray, Shafat Hameed, Analyzing the Effectiveness of Implementing Enterprise Resource Planning Systems in Priting Industry, European and Mediterranean Conference on Information Systems (EMCIS) 2006, July 6-7 2006, Costa Blanca, Alicante, Spain 